\title{
Preface of the "5th Symposium on Modelling and Simulation in Computer Sciences and Engineering"
}

Cite as: AIP Conference Proceedings 2293, 260001 (2020); https://doi.org/10.1063/5.0026557

Published Online: 25 November 2020

Francisco Miranda, Carlos Abreu, and Daniel Miranda

. Export Citation

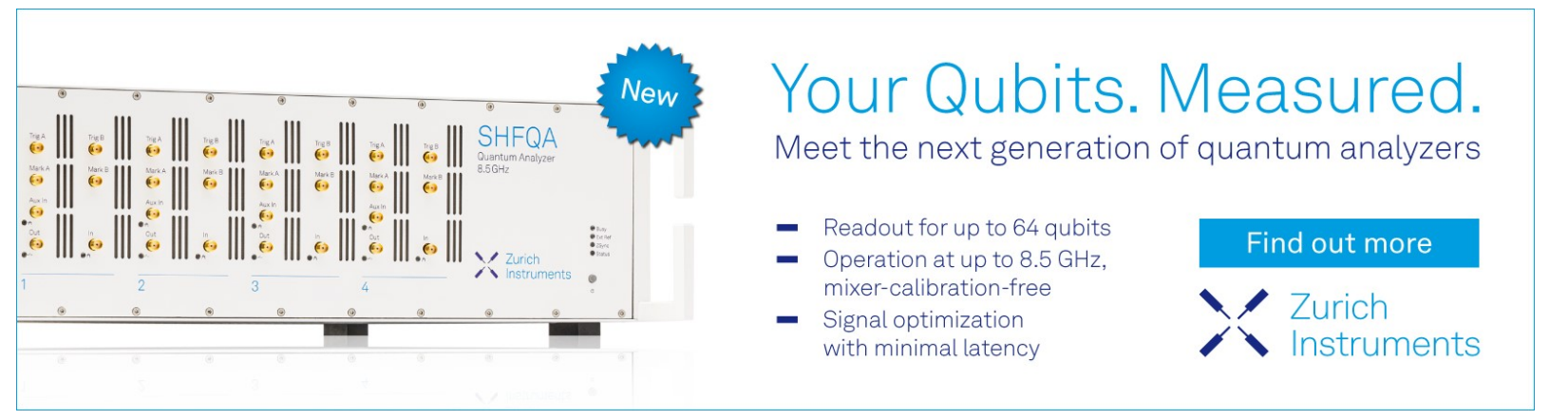




\title{
Preface of the "5th Symposium on Modelling and Simulation in Computer Sciences and Engineering"
}

\author{
Francisco Miranda ${ }^{1,2, a)}$, Carlos Abreu ${ }^{2, b)}$ and Daniel Miranda ${ }^{3, c)}$ \\ ${ }^{1}$ CIDMA, Universidade de Aveiro, Aveiro, Portugal \\ ${ }^{2}$ Instituto Politécnico de Viana do Castelo, Viana do Castelo, Portugal \\ ${ }^{3} 2$ Ai- Polytechnic Institute of Cávado and Ave, Barcelos, Portugal \\ ${ }^{a)}$ Corresponding author: fmiranda@estg.ipvc.pt \\ b)cabreu@estg.ipvc.pt \\ c)damiranda@ipca.pt
}

The 5th Symposium on Modelling and Simulation in Computer Sciences and Engineering was held in the 17th International Conference of Numerical Analysis and Applied Mathematics (ICNAAM 2019), Rhodes, Greece, 23-28 September 2019.

Modelling and simulation, applied to computer science and engineering, is an exciting research area that uses the computational power of modern information processing systems to improve our understanding of the real world. Computer simulations and graphical visualizations play a fundamental role in developing mathematical models to examine problems that would be too expensive, too much dangerous, or even impossible to study by direct experimentation. Moreover, virtual prototyping, using modelling and simulating software, is a keystone process to bring down the overall cost of designing and developing novel products. Indeed, the rising number of organisations using these technologies has led to a dramatic increase in demand for better research and skilled professionals in this research area.

As in the last symposia, that were great successes in ICNAAM 2014, 2015, 2016 and 2018, the aim of this 5th symposium was to provide research regarding modelling and simulation techniques applied to the physical sciences and engineering, where the purpose of the symposium activities was to discuss theoretical studies and experimental results with interest in several topics like modelling in engineering sciences and technology, dynamical systems models and methods, computational methods in engineering, computer science modelling and simulation, computer networks modelling, optimization, simulation and control theory, stochastic optimization, numerical methods and simulation, systems modelling, computational mathematics, analysis of mathematical models, algorithms and data structures, software design, control and systems engineering.

\section{ACKNOWLEDGMENTS}

The symposium organisers thank all the reviewers and the technical program committee for their assistance in the preparation of this important event. They also thank the organisers of the International Conference of Numerical Analysis and Applied Mathematics for allowing realize this symposium.

Technical Program Committee: António Abel Henriques, António Curado, António Mário L. F. Almeida, António Pinto, Bibudhendu Pati, Carla Barbosa, Carlos Costa, Chhabi Rani Panigrahi, Daniel Filipe Albuquerque, Estela Vilhena, Giovanni Pau, Helena Sofia Rodrigues, Hugo Rodrigues, Humberto Varum, Huseyin Yildirim Dalkilic, Isabel Gonçalves, James M. Raude, João F. Nunes, João Manuel R. S. Tavares, Manuel Rui Alves, Mariana Carvalho, Paula Alexandra Rego, Paulo Caldas, Pedro Dinho da Silva, Pedro Dinis Gaspar, Pijush Samui, Reza Gharoie Ahangar, Roohollah Kalatehjari, Rui Carneiro, S. Lanceros-Méndez, Sara Paiva, Sérgio Lopes, Sónia Dias, Torsten Hermanns, Vai Kuong Sin.

International Conference of Numerical Analysis and Applied Mathematics ICNAAM 2019

AIP Conf. Proc. 2293, 260001-1-260001-2; https://doi.org/10.1063/5.0026557

Published by AIP Publishing. 978-0-7354-4025-8/\$30.00 
The symposium was supported by the Portuguese Foundation for Science and Technology (FCT - Fundação para a Ciência e a Tecnologia), through CIDMA - Center for Research and Development in Mathematics and Applications, within project UID/MAT/04106/2019.

\section{Francisco Miranda}

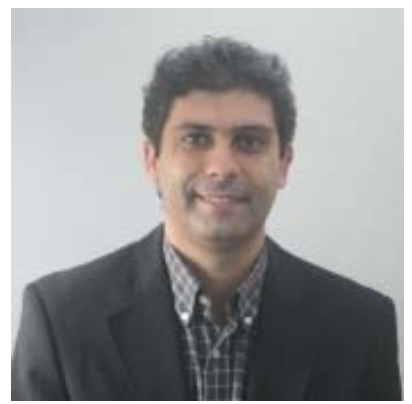

Francisco Miranda was born on April 1, 1975 in Viana do Castelo, Portugal. He graduated in Mathematics from University of Coimbra in 1999. Having done research on Control Theory he earned his MSc and PhD degrees in Applied Mathematics from University of Porto in 2003 and 2008, respectively. His research interests focus on stabilization and observability of control systems, optimal control, guidance control, numerical methods of stabilizer construction, time scales, Biomathematics and mathematical modelling in healthcare. Currently, he is Professor of Mathematics Department at Polytechnic Institute of Viana do Castelo, Portugal. He is also a researcher at Center for Research and Development in Mathematics and Applications, University of Aveiro, Portugal, and a research collaborator at Research Unit in Materials, Energy and Environment for Sustainability of Polytechnic Institute of Viana do Castelo, Portugal.

\section{Carlos Abreu}

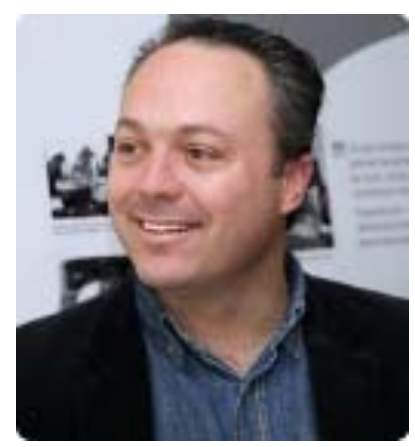

Carlos Abreu was born on September 8, 1976, in Esposende, Braga, Portugal. He graduated in Electronics and Telecommunications from the University of Aveiro in 2005. Having researched Instrumentation, Signal, and Medical Image, he received his MSc degree in Biomedical Engineering in 2008. In 2014, he earned his Ph.D. in Biomedical Engineering from the University of Minho, Portugal. His research interests focus on Biomedical Cyber-Physical Systems and Biomedical Data Science. Currently, he is working as Assistant Professor of Engineering at the Polytechnic Institute of Viana do Castelo (IPVC), Portugal.

\section{Daniel Miranda}

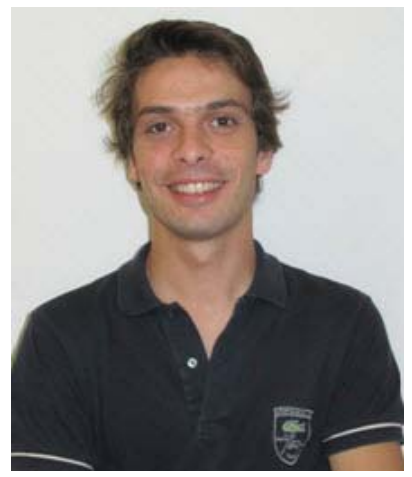

Daniel Miranda was born on May 18, 1981 in Viana do Castelo, Portugal. He graduated in Physics and Chemistry from University of Minho in 2005. In 2008, he obtained the MSc degree in Physics from the University of Minho. During his MSc thesis, he worked on Materials, Nanoscience, Nanotechnology, Processing and characterization on poly(vinylidene fluoride) doped with nano-silver particles. In 2017 he earned his $\mathrm{PhD}$ in Physics from the University of Minho, Portugal, with thesis theme: "Optimizing performance of rechargeable lithium-ion batteries through computer simulations". Currently, he is Adjunct Professor Invited at School of Technology, Polytechnic Institute of Cávado and Ave, Portugal, integrated member/researcher of $2 \mathrm{Ai}$ Laboratory at IPCA and researcher of Electroactive Smart Materials Research Group at University of Minho. He is currently focused on the development of theoretical models of lithium ion batteries through computational simulation (Finite Elements Method) and computational simulation and modeling applied in energy, energy systems, storage energy applications. Also, his current research interests focus on development of theoretical models and computational simulation applied in different areas, such as: supercapacitors, materials science (materials for energy applications: electrodes and battery separators), industrial applications and technologies (robotic, sensors, mechanics devices, thermodynamic systems or air conditioning systems, fluidic and microfluidic systems, electrical and electronic devices), health technologies (diagnostic systems), simulation systems and serious games. 